\title{
Primary lung adenocarcinoma: characteristics by smoking habit and sex
}

\author{
H. Nagy-Mignotte*,\#, , P. Guillem ${ }^{\star, \#}$, A. Vesin" ${ }^{\#}$ A.C. Toffart ${ }^{\uparrow}$, M. Colonna ${ }^{\#,+}$, \\ V. Bonneterre ${ }^{\S}$, P.Y. Brichon ${ }^{f}$, C. Brambilla ${ }^{\#,}$, E. Brambilla ${ }^{\#, * *}$, S. Lantuejoul**, \\ J.F. Timsit"\#,\# and D. Moro-Sibilot,\#, ${ }^{\star,}$, for the Multidisciplinary Thoracic Oncology \\ Group at Grenoble University Hospital
}

ABSTRACT: The incidence of adenocarcinoma is increasing, particularly among females. We sought to assess the role of tobacco consumption in clinical presentation according to sex.

In this retrospective study, 848 patients diagnosed between 1997 and 2006 at Grenoble University Hospital (Grenoble, France) were stratified into four groups according to smoking habits.

Differences between sexes and two contrasting female profiles emerged. Female current smokers were younger than female never-smokers (median 51 versus $69 \mathrm{yrs;} \mathbf{p}<\mathbf{0 . 0 0 1}$ ), more often had surgery $(62.7 \%$ versus $39 \% ; p=0.01)$ and had a median $(95 \% \mathrm{Cl}$ ) estimated survival of 26.2 (18.1-49.2) versus $15.1(12.8-22.2)$ months $(p=0.002)$. Both groups had similar survival when taking treatment into account. Among males, smoking did not influence presentation. Male current smokers were older than female current smokers (median 59 yrs; $\mathbf{p}<0.001$ ) and fewer had surgery (48.8\%; $p=0.015)$, although the percentage of stage IIIb-IV disease was similar $(53 \%$ and $46 \%$; nonsignificant) and they had a poorer estimated survival of $14.3(13.0-18.5)$ months $(p=0.0024)$. Males smoked more than females (median 41 versus 30 pack-yrs; $p<0.001$ ). Quitting smoking delayed age at diagnosis by 11 yrs for females $(p=0.0035)$ and 8 yrs for males $(p<0.001)$.

Our results support the hypothesis that carcinogenesis differs between males and females, and between female smokers and never-smokers.

\section{KEYWORDS: Primary lung adenocarcinoma, sex, smoking, survival}

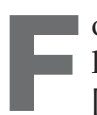
or over $20 \mathrm{yrs}$, the incidence of primary lung adenocarcinoma has been increasing $[1,2]$. Squamous cell carcinomas and small cell carcinomas (SCCs) are strongly linked to smoking [3-5] while adenocarcinoma is often found in females and never-smokers [2, 5-11]. There are large differences across studies in the characteristics of never-smokers with nonsmall cell lung cancer (NSCLC), including those with adenocarcinoma.

The multidisciplinary thoracic oncology meetings (MTOMs) that have been held since 1976 at Grenoble University Hospital (Grenoble, France) recommend a treatment strategy including palliative care, taking into account clinical presentation and cancer characteristics.

The proportion of adenocarcinoma cases discussed in these meetings increased from $22.7 \%$ between 1982 and 1986 to $42.9 \%$ between 2002 and 2006. For the period between 1997 and 2006, we also observed a higher proportion of never-smokers among adenocarcinoma patients $(15.3 \%)$ than among SSC and squamous cell cancer patients (23 (2.6\%) out of 885).

The aim of this study was to compare the characteristics and outcomes of patients with adenocarcinoma, between smokers and neversmokers according to sex.

\section{METHODS \\ Population}

This is an observational, single-centre study from the MTOMs of Grenoble University Hospital, a regional teaching hospital. All patients discussed at the MTOMs presenting with adenocarcinoma between 1997 and 2006 were included.

\section{Data collected}

Data were collected prospectively and recorded in the MTOM database. Information included age at first treatment, sex, characteristics of the tumour site (World Health Organization (WHO) International Classification of Diseases for Oncology), clinical and pathological TNM (tumour, metastasis and
AFFILIATIONS

*Oncology Coordination Centre,

"Pneumology Clinic,

Multidisciplinary Thoracic Oncology Group,

${ }^{\mathrm{s}}$ Centre for Occupational and

Environmental Diseases,

${ }^{f}$ Dept of Thoracic Surgery,

**Dept of Pathological Anatomy and Cytology,

\#\# Medical Intensive Care Unit, Grenoble University Hospital,

"INSERM Unit 823, Institute Albert

Bonniot, Joseph Fourier University,

Grenoble, and

${ }^{+}$Isere Cancer Register, Meylan,

France.

CORRESPONDENCE

H. Nagy-Mignotte

Centre de Coordination en

Cancérologie-3C

$\mathrm{CHU}$ de Grenoble

BP 217- 38043 Grenoble Cedex 9

France

E-mail: HMignotte@chu-grenoble.fr

Received:

Dec 132010

Accepted after revision:

May 042011

First published online:

Aug 042011 
node) staging (Union for International Cancer Control 1987-1998 and 2003), histological type (WHO Systematized Nomenclature of Medicine classification), WHO performance status (PS), tobacco consumption in pack-years, number of years since quitting, date of first treatment, locoregional recurrence, first metastasis and latest follow-up, vital status of patient, and, in the case of death, date and cause.

Data were extracted from the database on February 15, 2010 and vital status was also updated at this time. Patient outcomes were obtained from hospital records, well-established contacts with primary care physicians and municipal registries of deaths.

For never-smokers, any occupational exposure was identified through collaboration with the Dept of Occupational Disease (Grenoble University Hospital, Grenoble, France). The data from our hospital records were compared with data from the Isère Cancer Registry (County Epidemiological Register for Cancer, Meylan, France).

Patients were assigned to one of four groups according to their smoking habits at the date of treatment initiation [11]: 1) neversmokers ( $<100$ cigarettes in their whole life); 2) current smokers (patients still smoking or having quit within the past year); 3) former smokers (patients having quit $>1$ yr prior to the study); 4 ) undefined smokers (current or former smokers where information on quitting was unavailable). The undefined smoker group (four females and 22 males) is not specifically described here, but was included in the "smokers" group for statistics and survival curves.

For some analysis, patients with a history of smoking (current, former and undefined smokers) were grouped into a cohort called "smokers".

\section{Statistical analysis}

Only variables for which data were complete for $>80 \%$ of cases were used. The clinical characteristics of the different study groups were compared using Chi-squared or Fisher's tests and means were compared using unpaired t-tests. Median duration of follow-up was calculated using the inverted Kaplan-Meier method. The start date for survival was the date of first treatment.

The clinical variables suspected to be associated with survival were tested in univariate analysis using the nonparametric logrank test. Variables (except smoking-related variables) with $\mathrm{p}<0.2$ in the univariate analysis were subjected to a stepwise selection procedure for a multivariate Cox model (overall survival) or Fine and Gray model (lung cancer-specific survival). Variables with $\mathrm{p}<0.05$ in the multivariate analysis were retained in the model. Since the risk of death from lung cancer and death from another cause compete, the Cox model was not suitable for assessing lung cancer-specific survival (violation of uninformative censoring assumption). We therefore used the Fine and Gray model, which is an adaption of the Cox model that overcomes the uninformative censoring problem. The effect of smoking was tested by forcing the variable in the multivariate prognostic models (overall death and lung cancer-related death). p-values of $<0.05$ were considered significant. All statistical analyses were performed using SAS 9.13 (SAS Institute Inc., Cary, NC, USA).

\section{RESULTS}

We identified 984 adenocarcinomas and the study analysis concerned the 848 cases with documented smoking status, including $225(26.5 \%)$ females. Adenocarcinoma cases with missing smoking status were distributed equally by sex $(p=0.51)$. A comparison of our hospital data with the Isère Cancer Registry over a similar period showed no difference between the two populations concerning sex, median age at first treatment or histological type (online supplementary table 1).

\section{Exhaustivity}

We estimate that approximately $87 \%$ (95\% CI 71.0-96.5\%) of all types of lung cancer registered in the hospital database are discussed at the MTOM. Of the NSCLC patients reviewed in the study period, $12.1 \%$ were recommended to receive palliative care only.

\section{Age at first treatment}

The median age at first treatment was $61 \mathrm{yrs}$, with no significant differences between males and females (table 1). However, age at first treatment in female smokers was lower than in males (52 versus 62 yrs; $p \leqslant 0.001$ ). In contrast, among never-smokers, females were 8 yrs older than males $(p=0.037)$. For males, no difference in age was found between the different smoking groups. However, female current smokers were 18 yrs younger than female never-smokers $(p \leqslant 0.001)$ (online supplementary figs 1 and 2).

Quitting smoking delayed the median age of diagnosis by $8 \mathrm{yrs}$ for males and 11 yrs for females, in comparison with active smokers.

There was a higher percentage (23\%) of females than of males in the $<50$ yrs age group and among them, $86.5 \%$ were smokers and $73 \%$ still smoked (table 2 ). Their smoking profile was similar to that of males in the same age group. In contrast, males diagnosed before age 50 yrs made up only $11.7 \%$ of all males in the study population $(\mathrm{p} \leqslant 0.001)$.

In females, the proportion of never-smokers increased significantly with age from $13.5 \%$ at $<50$ yrs of age to $74.1 \%$ at $>70 \mathrm{yrs}$ of age. However, in males, this proportion did not vary with age, with an overall percentage of $4.8 \%$ (online supplementary fig. 3).

Diagnosis of adenocarcinoma in never-smokers $<50$ yrs of age was rare (1.4\% of cases), but with a significant difference between males (five out of 623) and females (seven out of 225) $(p=0.02)$ (table 2).

\section{Occupational exposure}

To try to explain age differences between male never-smokers and female never-smokers, we analysed data on occupational exposure in these groups (25 and 81 cases documented, respectively). Taking all types of exposure together, males underwent greater exposure (44\%) than females $(13.6 \%)$ $(p \leqslant 0.001)$. In particular, males were more frequently exposed to asbestos $(24 \%)$ than females $(3.7 \%)(p=0.005)$.

\section{Tobacco consumption}

Distribution by smoking status is given in table 2. Never-smokers represented $15.3 \%$ of patients, of whom $77 \%$ were females. While nearly half the females were never-smokers $(44.4 \%)$, only $4.8 \%$ of males had never smoked.

In current smokers, tobacco consumption was higher in males (median 50 pack-yrs, 95\% CI 46.7-53.3 pack-yrs) compared with 


\begin{tabular}{|c|c|c|c|c|c|}
\hline Subjects $n$ & 623 & 375 & 196 & 593 & 30 \\
\hline Median age yrs & 62 & 59 & 67 & 62 & 61 \\
\hline $95 \% \mathrm{Cl}$ & $61.0-63.0$ & $57.7-60.3$ & $65.3-68.6$ & $61.0-63.0$ & $55.9-66.1$ \\
\hline \multicolumn{6}{|l|}{ Females } \\
\hline Subjects n & 225 & 94 & 27 & 125 & 100 \\
\hline Median age at diagnosis yrs & 60 & 51 & 62 & 52 & 69 \\
\hline $95 \% \mathrm{Cl}$ & $57.9-62.1$ & $48.2-53.8$ & $56.2-67.8$ & $49.4-54.6$ & $66.3-71.7$ \\
\hline Range & $34-86$ & $34-86$ & $42-86$ & $34-86$ & $41-86$ \\
\hline \multicolumn{6}{|l|}{ All subjects } \\
\hline
\end{tabular}

females (35 pack-yrs, 95\% CI 29.9-40.1 pack-yrs) $(\mathrm{p} \leqslant 0.001)$. The same was true for the smokers group overall, with a median of 41 pack-yrs (95\% CI 38.3-43.7 pack-yrs) for males versus 30 packyrs (95\% CI 25.3-34.6 pack-yrs) for females ( $\mathrm{p} \leqslant 0.001)$. Age at first treatment was found to be directly related to the extent of tobacco consumption (fig. 1) for both sexes.

\section{Disease severity}

Disease severity varied according to smoking habit and sex (table 2). In females, never-smokers more often presented clinical stages IIIb and IV than current smokers $(p=0.01)$ or smokers $(p=0.03)$, and they were less frequently treated surgically. These differences were not significant between male groups. Male

\section{TABLE 2 Patients' characteristics}

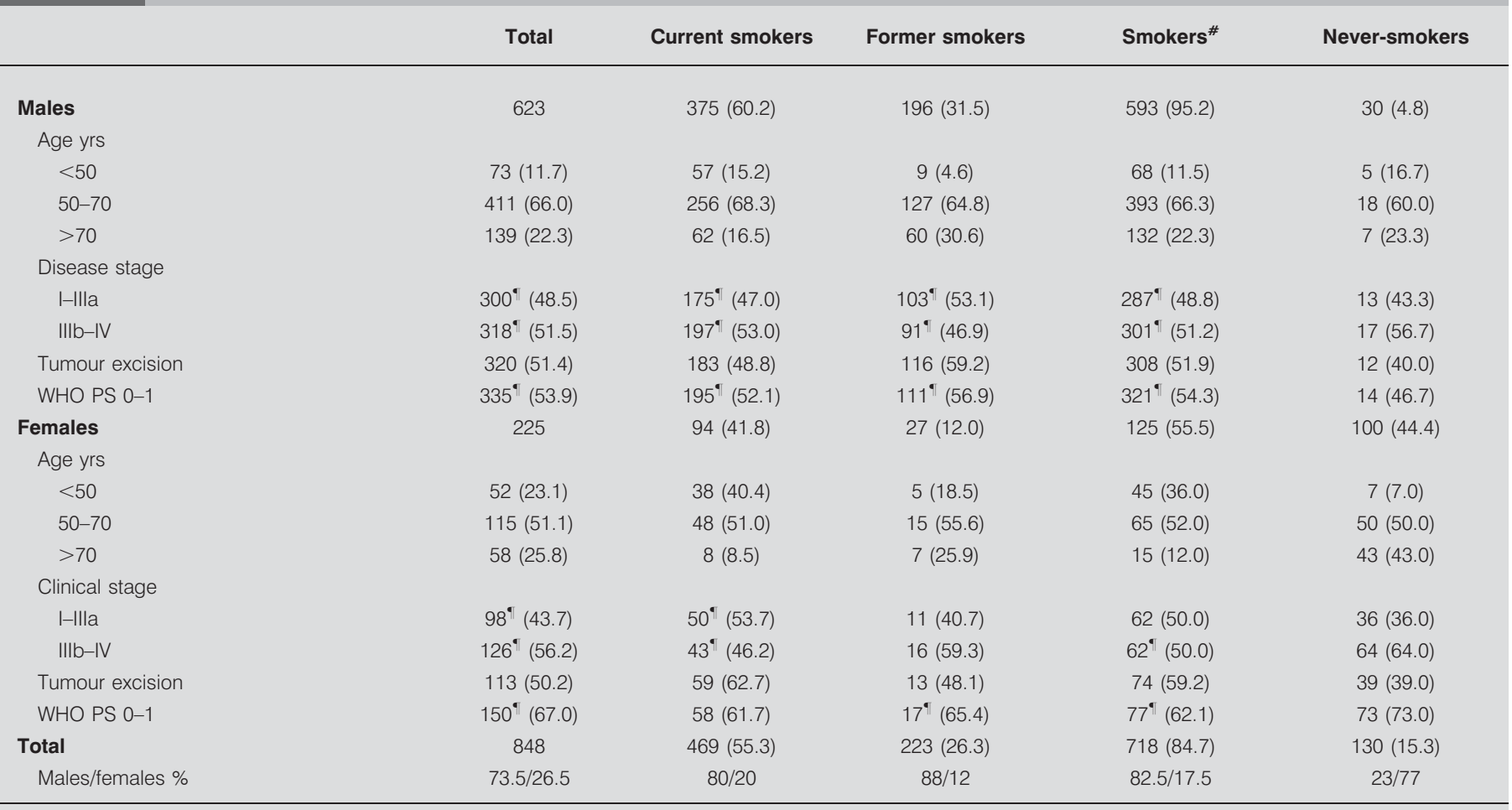

Data are presented as $\mathrm{n}$ or $\mathrm{n}(\%)$, unless otherwise stated. WHO: World Health Organization; PS: performance status. ${ }^{\#}$ : current, former smokers and undefined smokers; $\because$ one to five missing values. 

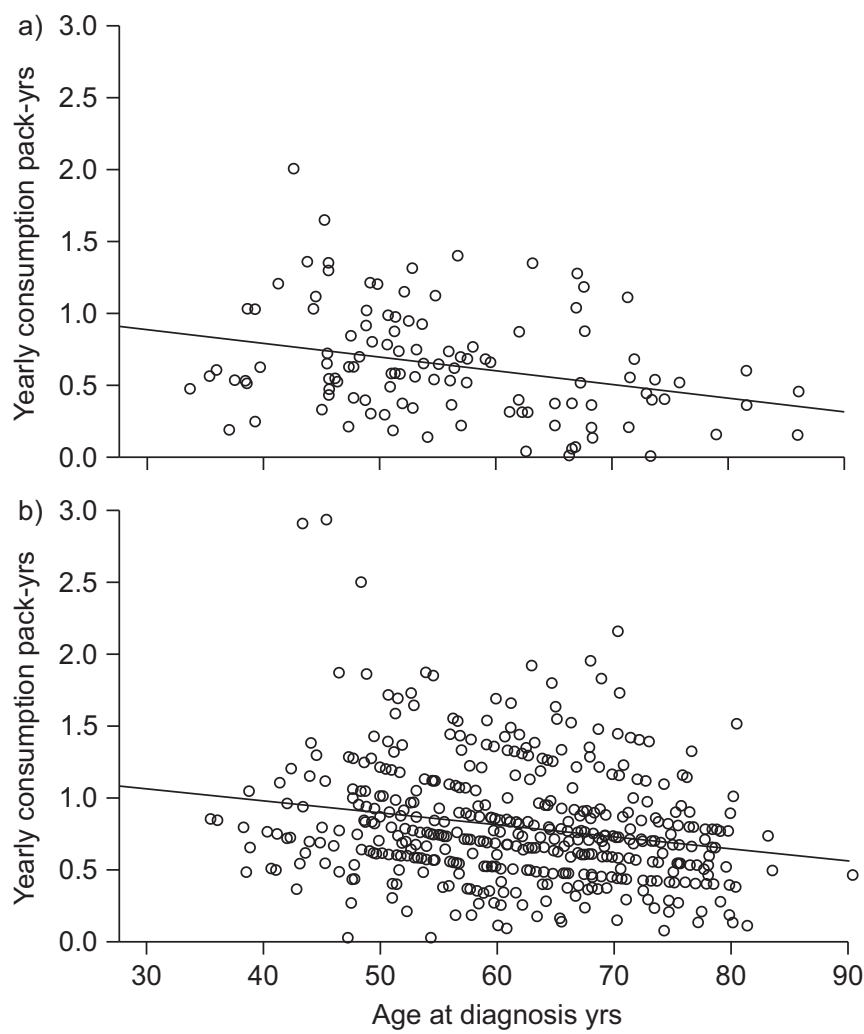

FIGURE 1. Relationship between mean pack-yrs and age at diagnosis for a) females $(r=-0.01, p=0.001)$ and $b)$ males $(r=-0.008, p \leqslant 0.0001)$.

current smokers underwent surgery less often than female current smokers $(p=0.015)$.

Females had a better PS than males $(p \leqslant 0.001)$ and in particular, female never-smokers had a better WHO PS than male neversmokers $(p=0.007)$ (table 2).

\section{Trends over time}

During the study period, the percentage of females diagnosed increased steadily, from $17.6 \%$ in 1997 to $31.1 \%$ in 2006 , while the proportion of female never-smokers decreased (online supplementary fig. 4).

\section{Survival}

Survival results are shown in table 3.14 (1.6\%) patients were lost to follow-up. The median follow-up was 50 months (95\% CI 4655 months). Of the females, 160 (71\%) out of 225 had died, including $66.4 \%$ of smokers and $77 \%$ of never-smokers. A slightly higher proportion of males had died (495 out of 623, 79.5\%), including $79.2 \%$ of smokers and $83 \%$ of never-smokers. Among the patients who died, $88.2 \%$ died from lung cancer (online supplementary table 2).

Female never-smokers, who were more often older and less likely to have been treated surgically, had a poorer prognosis than female smokers $(p=0.028)$ or female current smokers $(p=0.002)$. However, this difference disappeared when adjusting for therapeutic options (table 3; figs 2 and 3).
Significant differences in survival included longer survival for females versus males in both the smokers and current smokers groups $(p=0.002$ and $p=0.0024$, respectively).

In univariate analysis (table 4), factors reducing overall survival included older age, male sex, WHO PS $>1$, clinical stage $>$ IIIa, no surgery and year of treatment. The improved prognosis after 2004 might reflect the emergence of targeted therapies. Smoking status, extent of consumption and quitting smoking did not influence survival.

In multivariate analysis (table 5), the unfavourable prognostic factors were age $>70$ yrs, male sex, WHO PS $>1$, advanced clinical stage and no surgery. Smoking status did not influence survival (online supplementary table 3).

Analysis of specific deaths from cancer revealed the same risk factors in the univariate analysis (online supplementary table 4). However, in multivariate analysis, sex did not influence specific survival and current smoking seemed to be a detrimental factor in both sexes (online supplementary table 5).

\section{DISCUSSION}

Taking our results together, for females, we propose the following two contrasting patient profiles. 1) Female neversmokers were older, had few symptoms and were diagnosed later. Their median survival was comparable to that of male never-smokers but worse than that of young female smokers, although an analysis of survival according to surgery showed no significant difference. 2) Female current smokers were younger, smoked less than male current smokers and were in good physical condition. Surgery was more frequently feasible, with longer survival among female current smokers than the other groups, although 5-yr survival remained poor. Without surgery, the prognosis is highly pejorative and comparable to that of the much older female never smokers. For males, no specific profile in terms of smoking, age, PS, extent of tumour and survival could be proposed.

Our study confirms that adenocarcinoma is linked to smoking in males, but much less so in females. We found that a large number of never-smokers with adenocarcinoma were females $(77 \%)$, consistent with findings in the literature $[2,5,6,8,9,11-16]$.

Females who smoke are more often younger than male smokers $[9,10]$, with the average age difference being usually 3-6 yrs. An excess of females $<50$ yrs has also been noted by RADZIKOWSKA et al. [10] and in our study, $86.5 \%$ of this group were smokers.

For carriers of either adenocarcinoma or NSCLC, a median age ranging from 63.5 to 70 yrs can be found in the literature for never-smokers $[8,17]$, and a more advanced age for female neversmokers [2, 13]. However, the existence of two distinct generations of females presenting with adenocarcinoma depending on smoking status, has not previously been found and is particular to our study. This might be linked to later and less frequent smoking in females in Europe and our region of France than in the USA. The younger female smokers in our study were born between 1947 and 1956. They were teenagers or young adults in 1968 and represent the first generation to be influenced by more permissive attitudes towards smoking by females. In contrast, only Asian studies reveal adenocarcinoma patients in nonsmoking groups to be younger than those in smoker groups $[6,18]$. 


\begin{tabular}{|c|c|c|c|c|}
\hline & Subjects & Survival months & Alive at 3 yrs & Alive at $5 \mathrm{yrs}$ \\
\hline Current smokers & 375 & $14.3(13-18.5)$ & $119(31.7)$ & $93(24.8)$ \\
\hline Former smokers & 196 & $18.1(13.8-21.4)$ & 62 (31.6) & $50(25.5)$ \\
\hline \multicolumn{5}{|l|}{ Females } \\
\hline Current smokers & 94 & $26.2(18.1-49.2)$ & $42(44.7)$ & $37(39.4)$ \\
\hline Former smokers & 27 & $17.3(9.6-70.3)$ & $12(44.4)$ & $11(40.7)$ \\
\hline Never-smokers & 100 & $15.1(12.8-22.2)$ & $34(34.0)$ & $27(27.0)$ \\
\hline Smokers & 125 & $23.1(17.3-42.5)$ & $55(44.0)$ & $48(38.4)$ \\
\hline \multicolumn{5}{|l|}{ Treatment } \\
\hline \multicolumn{5}{|l|}{ Total } \\
\hline Current smokers & 469 & $16.9(13.9-20.4)$ & $161(34.3)$ & $130(27.7)$ \\
\hline Former smokers & 223 & $18.1(13.9-21.4)$ & 74 (33.2) & $61(27.4)$ \\
\hline Never-smokers & 130 & $16.8(13.8-22.2)$ & $42(32.3)$ & $32(24.6)$ \\
\hline Smokers & 718 & $17.3(14.5-19.2)$ & $242(33.7)$ & $194(27.0)$ \\
\hline
\end{tabular}

Data are presented as $\mathrm{n}$, median $(95 \% \mathrm{Cl})$ or $\mathrm{n}(\%)$. NA: not available.

We found that the proportion of female patients presenting with adenocarcinoma increased over time, reaching 31.1\% in 2006. In the USA the National Cancer Data Base reported, for the year 2001, 48\% females among patients presenting with adenocarcinoma and bronchoalveolar cancers [12]. According to Asian studies performed between 1999 and 2005, this proportion varied from $8.4 \%$ to $52.5 \%[3,9]$. These differences may reflect very different habits, exposure, and genetic and environmental factors between populations.

Our study confirms that females smoke less than males $[2,7,19]$ and supports the suggestion that they are more susceptible to

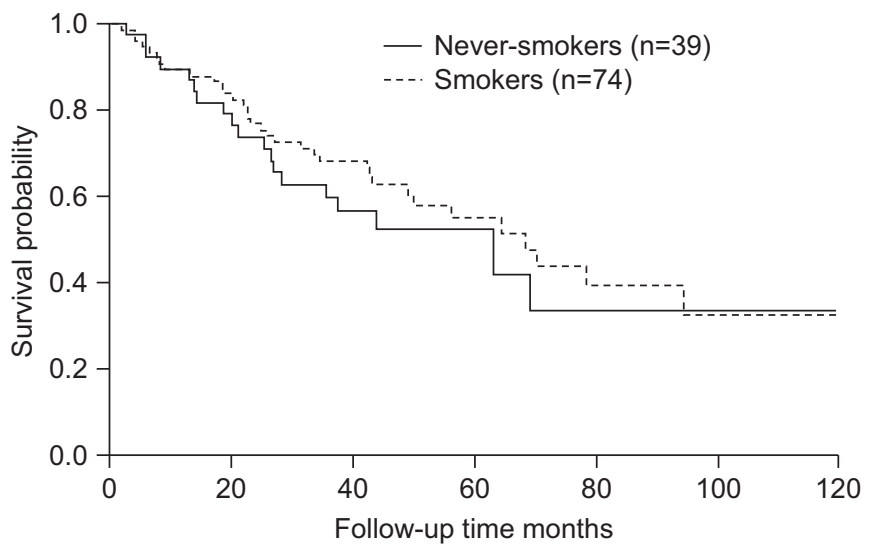

FIGURE 2. Survival by smoking habit for females treated with surgery. Among smokers, 34 (46\%) subjects died (median survival 68.3 months, 95\% Cl 49.2NA months). Among never-smokers, 20 (51\%) subjects died (median survival 63.1 months, 95\% Cl 28.4-NA months). Log-rank $p=0.45$. NA: not available. carcinogens in cigarette smoke [16]. However, we had no information on passive smoking in never-smoking patients, a recognised risk factor [2, 14, 15, 19-22], particularly in certain ethnic subgroups (e.g. Asian females) [17].

We confirm the beneficial effect of quitting smoking in both sexes, which can delay the age of onset by almost 10 yrs. We found no improved survival for the former smokers group, even among those having quit smoking for $>12$ yrs, but this group covers many different patterns of tobacco consumption. Females have a better performance status than males [7], as confirmed here, which is attributed to an excess of comorbidities in males related

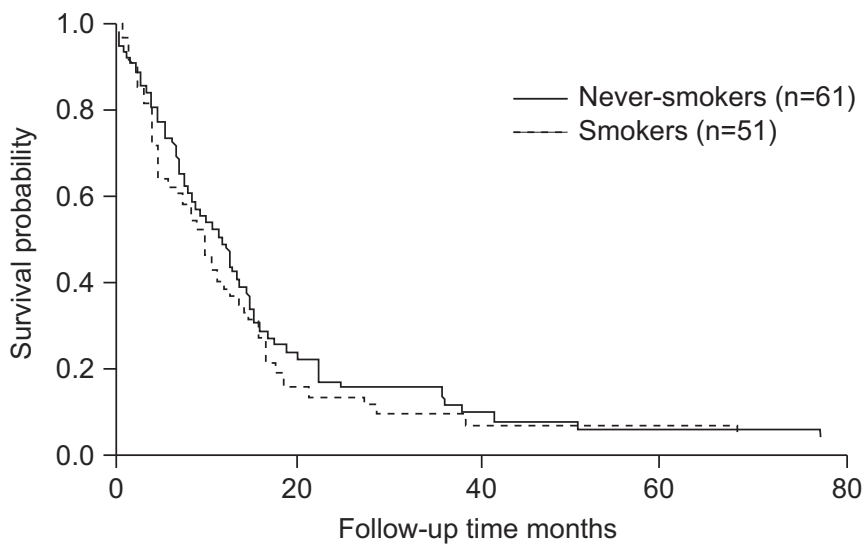

FIGURE 3. Survival by smoking habit for females not treated with surgery. Among smokers, 49 (96\%) subjects died (median survival 9.1 months, 95\% Cl 4.811.4 months). Among never-smokers, 57 (93\%) subjects died (median survival 11.3 months, $95 \% \mathrm{Cl} 7.4-13.7$ months). Log rank $p=0.33$ 
TABLE 4 Univariate risk factors for death from lung cancer

\begin{tabular}{|c|c|c|c|c|}
\hline Variable (missing values) & Alive & Died from cancer & Survival months & p-value ${ }^{\#}$ \\
\hline Subjects & 266 & 582 & & \\
\hline Female & $78(34.7)$ & $147(65.3)$ & $22.3(17.6-31.3)$ & 0.19 \\
\hline Male & $188(30.2)$ & $435(69.8)$ & $19.4(16.8-22.5)$ & \\
\hline \multicolumn{5}{|l|}{ Age yrs } \\
\hline $60-70$ & 81 (33.2) & $163(66.8)$ & $23.7(20.2-30.6)$ & \\
\hline$\geqslant 70$ & $56(26.5)$ & $155(73.5)$ & $13.8(12.8-18.8)$ & \\
\hline \multicolumn{5}{|l|}{ WHO PS (3) } \\
\hline 0 & $25(56.8)$ & 19 (43.2) & 87.1 (42.5-NA) & $<0.0001$ \\
\hline 1 & 170 (38.5) & 271 (61.5) & 33.8 (26.7-39.5) & \\
\hline$\geqslant 2$ & $68(18.9)$ & $292(81.1)$ & $10.7(8.7-13.3)$ & \\
\hline \multicolumn{5}{|l|}{ Year of treatment } \\
\hline$\leqslant 2001$ & $90(25.3)$ & $266(74.7)$ & $17.6(14.0-21.0)$ & 0.005 \\
\hline$>2001$ & $176(35.8)$ & $316(64.2)$ & $22.4(19.0-27.2)$ & \\
\hline$\leqslant 2004$ & $172(27.2)$ & $461(72.8)$ & $18.6(15.6-21.0)$ & 0.001 \\
\hline$>2004$, targeted therapy & $94(43.7)$ & $121(56.3)$ & $28.9(21.2-38.9)$ & \\
\hline \multicolumn{5}{|l|}{ Clinical stage (6) } \\
\hline la & $92(69.7)$ & $40(30.3)$ & NA & $<0.0001$ \\
\hline $\mathrm{lb}$ & $69(50)$ & $69(50)$ & 59.4 (43.3-NA) & \\
\hline$\| \mathrm{la} / \mathrm{llb}$ & $17(34.7)$ & $32(65.3)$ & $33.8(22.4-56.2)$ & \\
\hline$\| \mathrm{Il} / \mathrm{ll} \mathrm{b}$ & $56(26.3)$ & $157(73.7)$ & $16.0(13.2-20.4)$ & \\
\hline IV & $30(9.7)$ & $280(90.3)$ & $8.0(6.9-9.6)$ & \\
\hline \multicolumn{5}{|l|}{ Smoking } \\
\hline$<20$ & $57(31.1)$ & $126(68.9)$ & $21.0(17.2-26.8)$ & 1.0 \\
\hline $20-40$ & $60(32.3)$ & $126(67.7)$ & $20.9(15.7-31.4)$ & \\
\hline $40-50$ & $44(34.9)$ & $82(65.1)$ & $19.0(14.1-33.4)$ & \\
\hline$\geqslant 50$ & $77(30.8)$ & $173(69.2)$ & $21.4(18.5-25.8)$ & \\
\hline \multicolumn{5}{|l|}{ Stopped smoking (68) } \\
\hline Never-smokers & 35 (26.9) & $95(73.1)$ & $18.8(14.6-22.4)$ & 0.5 \\
\hline Quit $\leqslant 12$ yrs & 183 (32.3) & $383(67.7)$ & $20.9(17.6-24.9)$ & \\
\hline Quit >12 yrs & 27 (32.1) & 57 (67.9) & $20.4(13.8-32.0)$ & \\
\hline
\end{tabular}

Data are presented as $n, n(\%)$ or median $(95 \% \mathrm{Cl})$, unless otherwise stated. Median survival is artificially increased in censored patients to avoid the bias of "informed censoring" for patients who died from other causes. Bold indicates statistically significant $p$-values $(p \leqslant 0.05)$. WHO: World Health Organization; PS: performance status; NA: not available. ${ }^{\#}$ : Fine and Gray model.

to alcohol, greater occupational exposure and heavier smoking. The good WHO PS found in female never-smokers can be explained by less respiratory and cardiac comorbidity. At presentation for adenocarcinoma, they were older with more advanced clinical stages, suggesting a delay in diagnosis in this group, longer latency of the disease and/or a slower progression of the disease than in females who smoke. Also, the lack of respiratory and cardiac comorbidities, the good PS and lack of tobacco exposure mean that the primary care physician's attention is not drawn to the possibility of lung cancer.

Several authors have reported the advanced stage at diagnosis among female never-smokers, with $62.5-71 \%$ having stage $\mathrm{IIIb}-$ IV tumours in studies that focused on NSCLC $[8,14]$. At this late stage, recourse to surgery is limited for these female neversmokers and is the main handicap to their survival. 


\begin{tabular}{|c|c|c|}
\hline TABLE 5 & linical model $f$ & \\
\hline Parameter & HR $(95 \%$ Cl) & p-value \\
\hline \multicolumn{3}{|l|}{ Sex } \\
\hline Male & 1 & 0.01 \\
\hline Female & $0.79(0.66-0.95)$ & \\
\hline \multicolumn{3}{|l|}{ Age yrs } \\
\hline$\geqslant 70$ & $1.97(1.54-2.53)$ & $<0.0001$ \\
\hline $60-70$ & $1.24(0.97-1.59)$ & \\
\hline $50-60$ & $1.07(0.83-1.36)$ & \\
\hline$<50$ & 1 & \\
\hline \multicolumn{3}{|l|}{ WHO PS } \\
\hline $2-4$ & $1.60(1.35-1.89)$ & $<0.0001$ \\
\hline $0-1$ & 1 & \\
\hline Tumour excision & $0.41(0.33-0.50)$ & $<0.0001$ \\
\hline \multicolumn{3}{|l|}{ Clinical stage } \\
\hline IV & $2.70(2.10-3.48)$ & $<0.0001$ \\
\hline IIIa/b & $1.93(1.52-2.45)$ & \\
\hline$\| \mathrm{la} / \mathrm{b}$ & $1.37(0.95-1.97)$ & \\
\hline $\mathrm{la} / \mathrm{b}$ & 1 & \\
\hline
\end{tabular}

HR: hazard ratio; WHO: World Health Organization; PS: performance status. \#: $n=787$; ${ }^{\bullet}$ : Cox proportional hazard model.

In the never-smokers group, in agreement with the literature, we confirm the prevalence of occupational exposure in males $[2,14,16,22]$. This could explain the younger median age at diagnosis, by 8 yrs, for males compared with females.

Ultimately, the large proportion of female never-smokers and the earlier age of onset of adenocarcinoma in females who smoke, albeit less than males, suggest an increased susceptibility in females. In the literature, we find this notion of "greater susceptibility" among females, who accumulate multiple deficits: reduced clearance of nicotinic derivatives, poorer ability to repair DNA, and an activating role of certain hormones, such as gastrinreleasing peptide and oestrogens, all of which may contribute to "accelerated" carcinogenesis [2, 15, 16, 22, 23]. This could explain the poorer survival of female smokers, particularly when surgery is no longer feasible (fig. 3), supporting the hypothesis of a more aggressive tumour.

Differences in clinical presentation support the hypothesis that carcinogenesis differs between smokers and never-smokers $[2,11$, $14,24]$, and between males and females [2, 5, 16, 25], as evidenced by the greater proportion of epidermal growth factor receptor mutations, with greater sensitivity to tyrosine kinase inhibitors in female never-smokers. However, some authors dispute such differences [26].

Males with adenocarcinoma have been found to have a history of tobacco consumption similar to that for other histological types of tumour, such as squamous cell carcinoma and SCC. The tendency towards adenocarcinoma might be explained by the composition of cigarette smoke [2].

For equivalent levels of smoking, females have a better prognosis than males. This observation is found in numerous studies with uni- or multivariate analysis for NSCLC or adenocarcinoma alone $[7,9,10,16,25]$.
We found neither overall survival nor lung cancer survival to be significantly influenced by smoking in either the uni- or multivariate analysis for either sex. In contrast to observations in some cohorts $[9,11,14,17,18]$, the prognosis for neversmokers was no better than for smokers. The younger age of female smokers and earlier diagnosis made surgical intervention more feasible, explaining their better survival than female never-smokers. Nevertheless, their prognosis remained poor, with low rates of 5-yr survival. The message of prevention by abstaining from smoking is still highly relevant, especially as young female smokers presenting at an inoperable stage have catastrophic survival. Other authors have found similar survival for NSCLC in smokers and never-smokers $[6,8]$ but without any distinction by sex. The excess of deaths in never-smoking males compared with never-smoking females is also controversial [26, 27].

Survival and presentation of adenocarcinoma as a function of smoking varies between studies and differences may be explained by the heterogeneity in the populations analysed and in the comparisons made.

Our study has several limitations. This was a single-centre, retrospective, observational study conducted at a large regional university hospital. However, on the basis of comparisons made with the cancer registry data, we believe that the study population is representative of our region. We were not able to discuss all of the lung cancer cases presenting at the hospital. However the vast majority of these cases were included in the study. The missing cases were mainly patients with very poor prognosis with no therapeutic outcome. A potential bias is the underestimation of pack-years for smokers because of the possible subjectivity of this information, which was collected during the initial and subsequent medical consultations.

\section{Conclusion}

We confirm the disturbing susceptibility of females to adenocarcinoma. The study highlights major differences in presentation between females according to smoking status, leading to the existence of different "generations" of female patients.

For female never-smokers, we hypothesise a disease with extended latency, explaining the often pejorative presentation, relatively late diagnosis and poor prognosis, although the advent of targeted therapies and earlier diagnosis may change this outcome. In contrast, young female smokers who smoked less than males and for whom surgery was not feasible had a very poor survival rate. This argues for a particularly aggressive form of the disease, greater susceptibility and accelerated carcinogenesis.

Differences in clinical presentation between female smokers and never-smokers and the absence of specificity in males raise the question as to whether there are differences in carcinogenesis between males and females, and between female smokers and female never-smokers. Variations in mutational profile between smokers and never-smokers might provide the beginning of an explanation [11, 18, 24] and give hope for a better therapeutic response to targeted therapies (the INTEREST (Iressa Non-Small Cell Lung Cancer Trial Evaluating Response and Survival Against Taxotere) study) [28]. Diagnostic innovations, such as the development of a tumour identity card, could facilitate these tailored therapeutic applications $[29,30]$. 
These results provide an incentive to improve preventive measures targeted at females and to alert primary care physicians to the risks of adenocarcinoma in female neversmokers.

\section{SUPPORT STATEMENT}

Translation and critical editing of this manuscript was supported by Eli Lilly laboratories (Suresnes, France).

\section{STATEMENT OF INTEREST}

A statement of interest for the study itself can be found at www.erj. ersjournals.com/site/misc/statements.xhtml

\section{ACKNOWLEDGEMENTS}

We thank all the participating doctors, and the members of the Oncology Coordination Centre at Grenoble University Hospital and the Alpine Cancer Network. We are grateful to A. Foote (Grenoble Clinical Research Centre, INSERM CIC03, Grenoble, France) and S. Carrodus (freelance translator, Grenoble, France) for translating and critically editing the manuscript.

\section{REFERENCES}

1 Santos-Martinez MJ, Curull V, Blanco ML, et al. Lung cancer at a university hospital: epidemiological and histological characteristics of a recent and a historical series. Arch Bronconeumol 2005; 41: 307-312.

2 Quoix E. Novel epidemiology in lung cancer - non-smokers, females and cannabis. Rev Mal Respir 2007; 24: Suppl. 6, S10-S15.

3 Toh CK, Gao F, Lim WT, et al. Differences between small-cell lung cancer and non-small-cell lung cancer among tobacco smokers. Lung Cancer 2007; 56: 161-166.

4 Agudo A, Ahrens W, Benhamou E, et al. Lung cancer and cigarette smoking in females: a multicenter case-control study in Europe. Int J Cancer 2000; 88: 820-827.

5 Gazdar AF, Thun MJ. Lung cancer, smoke exposure, and sex. J Clin Oncol 2007; 25: 469-471.

6 Toh CK, Wong EH, Lim WT, et al. The impact of smoking status on the behaviour and survival outcome of patients with advanced non-small cell lung cancer: a retrospective analysis. Chest 2004; 126: $1750-1756$

7 De Perrot M, Licker M, Bouchardy C, et al. Sex differences in presentation, management, and prognosis of patients with nonsmall cell lung carcinoma. J Thorac Cardiovasc Surg 2000; 119: 21-26.

8 Subramanian J, Velcheti V, Gao F, et al. Presentation and stagespecific outcomes of lifelong never-smokers with non-small cell lung cancer (NSCLC). J Thorac Oncol 2007; 2: 827-830.

9 Hsu LH, Chu NM, Liu CC, et al. Sex-associated differences in nonsmall cell lung cancer in the new era: is gender an independent prognostic factor? Lung Cancer 2009; 17: 262-267.

10 Radzikowska E, Glaz P, Roszkowski K. Lung cancer in females: age, smoking, histology, performance status, stage, initial treatment and survival. Population-based study of 20561 cases. Ann Oncol 2002; 13: 1087-1093.
11 Sun S, Schiller JH, Gazdar AF. Lung cancer in never-smokers: a different disease. Nature 2007; 7: 778-790.

12 Little AG, Gay EG, Gaspar LE, et al. National survey of non-small cell lung cancer in the United States: epidemiology, pathology and patterns of care. Lung Cancer 2007; 57: 253-260.

13 Wakelee HA, Chang ET, Gomez SL, et al. Lung cancer incidence in never-smokers. J Clin Oncol 2007; 25: 472-478.

14 Subramanian J, Govindan R. Lung cancer in never-smokers: a review. J Clin Oncol 2007; 25: 561-570.

15 Akazawa Y, Satoh H, Takeda YY, et al. Significantly lower rate of smoking in female compared to male patients with lung adenocarcinoma. Eur J Cancer Care 2003; 12: 283-285.

16 Barnes DJ. The changing face of lung cancer. Chest 2004; 126: 1718-1721.

17 Nordquist LT, Simon GR, Cantor A, et al. Improved survival in never- smoker vs current smokers with primary adenocarcinoma of the lung. Chest 2004; 126: 347-351.

18 Toh CK, Gao F, Lim WT, et al. Never-smokers with lung cancer: epidemiologic evidence of a distinct disease entity. J Clin Oncol 2006; 24: 2245-2251.

19 Epplein M, Schwartz SM, Potter JD, et al. Smoking-adjusted lung cancer incidence among Asian-Americans (United States). Cancer Causes Control 2005; 16: 1085-1090.

20 De Andrade M, Ebbert JO, Wampfler JA, et al. Environmental tobacco smoke exposure in females with lung cancer. Lung Cancer 2004; 43: 127-134.

21 Kurahashi $\mathrm{N}$, Inoue $\mathrm{M}$, Liu $\mathrm{Y}$, et al. Passive smoking and lung cancer in Japanese non-smoking females: a prospective study. Int $J$ Cancer 2008; 122: 653-657.

22 Quoix E, Mennecier B. Cancer du poumon et pollution [Lung cancer and pollution]. Rev Pneumol Clin 2003; 59: 187-195.

23 Quoix E. Particularités du cancer bronchique chez la femme [Particularities of lung cancer in women]. Rev Pneumon Clin 2004; 60: 27-30.

24 Toyooka S, Tokumo M, Shigematsu $\mathrm{H}$, et al. Mutational and epigenetic evidence for independent pathways for lung adenocarcinomas arising in smokers and never-smokers. Cancer Res 2006; 66: 1371-1375.

25 Quoix E. Specific features of bronchial cancer in females. Rev Pneumol Clin 1999; 55: 290-295.

26 Freedman ND, Leitzmann MF, Hollenbeck AR, et al. Cigarette smoking and subsequent risk of lung cancer in males and females: analysis of a prospective cohort study. Lancet 2008; 9: 649-656.

27 Thun MJ, Hannan LM, Adams-Campbell LL, et al. Lung cancer occurrence in never-smokers: an analysis of 13 cohorts and 22 cancer registry studies. PLoS Med 2008; 5: e185.

28 Douillard JY, Shepherd FA, Hirsh V, et al. Molecular predictors of outcome with gefitinib and docetaxel in previously treated non-small-cell lung cancer: data from randomized phase III INTEREST trial. J Clin Oncol 2010; 28: 744-752.

29 Pao W, Kris MG, Lafrate AJ, et al. Integration of molecular profiling into the lung cancer clinic. Clin Cancer Res 2009; 15: 5317-5322.

30 Field JK, Liloglou T, Niaz A, et al. EUELC project: a multi-centre, multipurpose study to investigate early stage NSCLC, and establish a biobank for ongoing collaboration. Eur Respir J 2009; 34: 1477-1486. 